\title{
ANALGESIC, ANTI-INFLAMMATORY AND ANTIPYRETIC ACTIVITIES OF THE AQUEOUS EXTRACT OF GERANIUM CAROLINIANUM L
}

\author{
Yuan $\mathrm{Li}^{1,2 \#}$, Ying Ye ${ }^{1 \#}$, Su-Juan Wang ${ }^{1}$, Wei Xia ${ }^{3}$, Khalid Rahman ${ }^{4}$, Wei Yue ${ }^{1}$, Hong Zhang ${ }^{12^{*}}$ \\ ${ }^{1}$ Central Laboratory, Shanghai Seventh People's Hospital, Shanghai 200137, P. R. China \\ ${ }^{2}$ Department of Pharmaceutical Botany, School of Pharmacy, Second Military Medical University, Shanghai 200433, \\ P. R. China, ${ }^{3}$ Department of Nuclear Medicine, Shanghai Seventh People's Hospital, Shanghai 200137, P. R. China \\ ${ }^{4}$ School of Pharmacy and Biomolecular Sciences, Faculty of Science, Liverpool John Moores University, Liverpool \\ L3 3AF, England, UK. \\ \#These authors contributed equally to the work
}

Corresponding Author: E-mail: hqzhang51@126.com

\begin{abstract}
Background: Geranium carolinianum L. (Geraniaceae) is widely used for a variety of diseases including herpetic keratitis, eczema, rheumatalgia etc. However, there is lack of relevant scientific research.

Materials and Methods: $\operatorname{GCE}(125,250,500 \mathrm{mg} / \mathrm{kg}$ body weight) was evaluated for its pharmacological properties by using the acetic acid-induced writhing test, the hot plate test and the fresh egg white-induced paw edema in rats. The dimethylbenzene-induced mouse inflammation model and the lipopolysaccharide (LPS)-induced rat fever model were employed and the acute toxicity of GCE was also assessed.

Results: The Geranium carolinianum aqueous extract (GCE) significantly inhibited the writhing responses in mice, increased reaction time of mice in the hot plate test, and suppressed the fresh egg white-induced paw edema in rats and the dimethylbenzene-induced ear edema in mice whilst attenuating LPS-induced fever in rats in a dose dependent manner. Furthermore, no deaths were observed when mice were orally administered GCE up to $14 \mathrm{~g} / \mathrm{kg}$ body weight (approximately 553 times of clinical dose).

Conclusions: GCE possesses analgesic, anti-inflammatory and antipyretic activities and is non-toxic at the doses used. The results of this study support the clinical use and effectiveness of Geranium carolinianum as an analgesic, anti-inflammatory and antipyretic agent in folk medicine.
\end{abstract}

Key words: Plant drug; Pain; Inflammation; Pyrexia; Toxicity; Animal

\section{Introduction}

Geranium carolinianum L. (Geraniaceae) is a commonly used herb in folk medicine for the treatment of herpetic keratitis, rheumatilc arthritis arthralgia, disc prolapsed, gastrointestinal disorders, bacillary dysentery, ferbile diseases etc. It has a wide distribution in North East China, East China, Central China and Sichuan Province (Han et al., 2001; Wu et al., 2008). One of the most important clinical applications of this herb is in the treatment of herpetic keratitis (Wang et al., 1995). In addition, Geranium carolinianum ointment is reported to be a good therapy for eczema and herpes zoster (Han et al., 2001). Geranium carolinianum has been recorded as a Chinese herb in the Chinese Pharmacopoeia owing to its exact curative effects.

The phytochemical study of Geranium carolinianum reveals the presence of tannins, flavones, flavonoids, volatile oils and organic acids (Lei et al., 2002), which have been extracted from Geranium carolinianum as well as most of the congeneric plants (He et al., 2011). This plant possesses a variety of pharmacological effects, such as antibacterial, antiviral, antioxidant, antitumor, hypoglycemic, liver protecting, and cough relieving properties ( $\mathrm{Li}$ et al., 2008; Wu et al., 2011). The water extract from Geranium carolinianum contains 5-40\% of corilagin, which is known to be effective in the treatment of gastroxia (Li et al., 2009) 


\section{http://dx.doi.org/10.4314/ajtcam.v13i1.15}

As far as we are aware, there have been no scientific reports on the analgesic, antipyretic, and anti-inflammatory effects of this plant in animals. In this study, we report these activities of the aqueous extract of Geranium carolinianum which were evaluated in mice and rats to substantiate and expand its clinical applications. In addition, the acute oral toxicity of the extract was also determined in mice.

\section{Materials and Methods \\ Plant Material and Extraction}

The whole plant of Geranium carolinianum was collected in Great Khingan of Heilongjiang Province in September 2013 and the plant was identified by Professor Han-Ming Zhang, a pharmacognosist from the Department of Pharmacognosy, School of Pharmacy, Second Military Medical University (Shanghai, China). A voucher specimen of Geranium carolinianum was deposited and assigned the number YZ130905 in the herbarium of the Department of Pharmaceutical Botany, School of Pharmacy, Second Military Medical University (Shanghai, China). The dried plant $(500 \mathrm{~g})$ was pulverized with amotor-driven grinder to prepare the extract which was then refluxed with distilled water $(8 \mathrm{~L})$ three times for $0.5 \mathrm{~h}, 1 \mathrm{~h}$, and $2 \mathrm{~h}$, respectively. The extract was then filtered, centrifuged and evaporated to dryness under reduced pressure in a rotary evaporator and the dry powder was obtained by spray drying and a yield of $10.13 \%$ was achieved.

\section{Chromatographic Conditions}

An Agilent 1100 HPLC system equipped with a quaternary pump, an auto-sampler, a degasser, an automatic thermostatic column compartment, a DAD and an LC/MSD Trap XCT ESI mass spectrometer (Agilent Technologies, MA, USA), was used for separation. The separation was performed on a GS-120-5-C18-BIO chromatographic column $(5 \mu \mathrm{m}, 250 \times 4.6 \mathrm{~mm}$ i.d.) with the column temperature set at $35^{\circ} \mathrm{C}$. A linear gradient elution of A $(0.1 \%$ formate acid water) and B (acetonitrile) was used with the gradient procedure as follows: 0 min, B $5 \%$, to $60 \mathrm{~min} \mathrm{~B} 40 \%(\mathrm{v} / \mathrm{v})$. The flow rate was $1.0 \mathrm{~mL} / \mathrm{min}$ and the injection volume was $10 \mu \mathrm{L}$. DAD was on and the target wavelength was simultaneously set at $210 \mathrm{~nm}$. The split ratio to the mass spectrometer was 1:3. The acquisition parameters for negative ion mode were: collision gas, ultrahigh-purity helium (He), nebulizer gas (N2), 35 psi, drying gas (N2), $10 \mathrm{~L} / \mathrm{min}$, drying temperature, $350^{\circ} \mathrm{C}, \mathrm{HV}, 3500 \mathrm{~V}$, mass scan range, m/z 100-2200, target mass, $500 \mathrm{~m} / \mathrm{z}$, compound stability, $100 \%$, trap drive level, $100 \%$. All the data were analyzed by Chemstation software.

\section{Animals}

ICR mice (age range8-10 weeks, weight range 20-25g), male Sprague-Dawley (SD) rats (age range 8-9 weeks, weight range 200-220 g) and male Wistar rats (age range 7-9 weeks, weight range 200-220 g), were obtained from the Experimental Animal Center of the Second Military Medical University (Shanghai, China), and were housed in a regulated environment $\left(20 \pm 2^{\circ} \mathrm{C}\right)$, with a $12 \mathrm{~h} \mathrm{light/dark}$ cycle (08:00-20:00, light). The animals were deprived of food for $12 \mathrm{~h}$ prior to the experiment, with water given ad libitum and each animal was used once in the experiment. All animal treatments were strictly in accordance with international ethical guidelines concerning the care and use of laboratory animals, and all the experiments were carried out under the approval of the Committee of Experimental Animal Administration of the University (No. LL130929). Each experimental group consisted of 10 animals.

\section{Drugs and Reagents}

The following reagents and drugs were used: dimethylbenzene (AR), and acetic acid (AR) (Sinopharm Chemical Reagent, Shanghai, China), lipopolysaccharide (Sigma, St. Louis, MO, USA), tramadol, indomethacin, dexamethasone, paracetamol (Chengdu Pharmaceutical Factory, Chengdu, China).

\section{Treatment}

GCE, indomethacin, dexamethasone, paracetamol, and tramadol were each suspended in $1 \%$ carboxymethylcellulose sodium (CMC-Na) 


\section{http://dx.doi.org/10.4314/ajtcam.v13i1.15}

solution respectively prior to administration. GCE at a concentration range of $125,250,500 \mathrm{mg} / \mathrm{kg}$ body weight was orally administered to the three groups of animals $(\mathrm{n}=10)$ respectively by intubation. The positive group of animals received indomethacin $(5 \mathrm{mg} / \mathrm{kg})$ in the writhing and paw edema tests, tramadol $(30 \mathrm{mg} / \mathrm{kg})$ in the hot plate test, dexamethasone $(5 \mathrm{mg} / \mathrm{kg})$ in the ear edema test and paracetamol $(100 \mathrm{mg} / \mathrm{kg})$ in the antipyretic test, respectively. The control group of animals was given 1\% CMC-Na solution and it established alongside the drug-treated groups, all of which received a volume of $10 \mathrm{~mL} / \mathrm{kg}$ body weight irrespective of dose.

\section{Analgesic Test}

The peripheral and central analgesic activity of GCE was investigated by monitoring test animals exposed to chemical and thermal stimuli respectively. In the acetic acid-induced writhing test (Garcia et al., 2004), male mice were orally administered GCE or indomethacin $(5 \mathrm{mg} / \mathrm{kg}$ body weight) respectively, $1 \mathrm{~h}$ prior to intra-peritoneal injection of acetic acid $(1 \%, 10 \mathrm{~mL} / \mathrm{kg}$ body weight). The number of writhing reflexes was then counted for a period of $15 \mathrm{~min}$.

In the hot plate test (Ma et al., 2011; Xu et al., 2002), the latency was recorded when female mice were screened on the hot plate at $55 \pm 0.5^{\circ} \mathrm{C}$. Only mice that showed initial nociceptive responses between 5 and $30 \mathrm{sec}$ were selected for this experiment. The post-treatment reaction time of each animal was recorded by observing either the licking of the hind paws or the jumping movements to avoid thermal pain after 30, 60, 90, and $120 \mathrm{~min}$ respectively of administration of GCE or tramadol (30 $\mathrm{mg} / \mathrm{kg}$ body weight).

\section{Anti-Inflammatory Test}

The anti-inflammatory activity of GCE was measured against fresh egg white induced acute paw edema in rats (Xu et al., 2002) and dimethylbenzene induced ear edema in mice (Ma et al., 2011; Zheng et al., 2009). In the rat paw edema test, male SD rats were orally pre-medicated with GCE or indomethacin $(5 \mathrm{mg} / \mathrm{kg}$ body weight) $0.5 \mathrm{~h}$ prior to sub-plantar injection of $0.1 \mathrm{~mL}$ freshly prepared $10 \%$ (v/v) egg white solution into the right hind paws of the rats. Paw volume was measured plethysmometrically using a paw edema detector (YLS-7A; Shandong Academy of Medical Science Device Station, Shandong, China) at 0, 0.5, 1, 2, 3, 4, and 6 h post-injection. The mean increase in paw volume was measured and inhibitory percentage was calculated. The edema rate of rats was calculated as follows:

Edema rate $(\%)=\left(\mathrm{V}_{\mathrm{t}}-\mathrm{V}_{0}\right) / \mathrm{V}_{0} \times 100 \%$

Where $\mathrm{V}_{0}$ is the volume before fresh egg white injection $(\mathrm{mL}) ; \mathrm{V}_{\mathrm{t}}$ is the volume after $\mathrm{t}$ h of fresh egg white injection $(\mathrm{mL})$.

In the dimethylbenzene-induced ear edema test, GCE or dexamethasone ( $5 \mathrm{mg} / \mathrm{kg}$ body weight) was orally administered $1 \mathrm{~h}$ prior to local application of dimethylbenene ( $40 \mu \mathrm{L} / \mathrm{ear})$ to the right ear of mice. The ear swelling was measured by subtracting the weight of the left ear from that of the right post $1 \mathrm{~h}$ of dimethylbenzene treatment as reported previously (Zheng et al., 2009).

\section{Antipyretic Test}

The antipyretic activity of GCE was investigated according to the method previously reported (Ma et al., 2011). Male SD rats were randomly divided into five groups based on their basal temperature measured prior to the experiment. The temperature in external auditory meatus was measured in a temperature-controlled room (ambient temperature $20 \pm 2^{\circ} \mathrm{C}$ ) using an electronic temperature recorder (DT-IDB, Shanghai Medical Instruments Factory, Shanghai). Rat fever can be induced by intra-peritoneal injection of LPS (1 mg/kg). SD rats were pretreated with LPS post $0.5 \mathrm{~h}$ of oral administration of GCE or paracetamol (100 mg/kg body weight). The temperature was measured every $30 \mathrm{~min}$ from 9:00 hrs to 15:00 hrs.

\section{Acute Toxicity}

Acute toxicity study was carried out as reported in the literature (Saha et al., 2013). ICR mice of either sex were tested by orally administering different doses of the extract by increasing or decreasing the dose according to the responses of the animals. The animals were fasted overnight and had access to water only prior to the experiment. The animals were administered GCE at a dose of $14 \mathrm{~g} / \mathrm{kg}$ body weight and were test for any toxic signs or mortality for 7 days. 


\section{http://dx.doi.org/10.4314/ajtcam.v13i1.15}

\section{Li et al., Afr J Tradit Complement Altern Med. (2016) 13(1):105-113}

Statistical Analysis: The data was analyzed using a SPSS 13.0 statistical package, and data for multiple comparisons was performed by one-way ANOVA followed by Tukey's test. A value of $\mathrm{P}<0.05$ was considered statistically significant and all results are presented as mean \pm SD.

\section{Results}

\section{Identification of Compounds}

The aqueous extract of Geranium carolinianum (GCE) was measured by high-performance liquid chromatography coupled with electrospray mass spectrometry (HPLC/ESI-MS) in negative-ion mode (Figure $1 \mathrm{a}-\mathrm{g}$ ). Five compounds 1-5, with the retention time at 7.1 min, $19.2 \mathrm{~min}, 21.7 \mathrm{~min}, 29.8 \mathrm{~min}$, and $30.5 \mathrm{~min}$, were identified as gallic acid (1), brevifolin carboxylic acid (2), corilagin (3), ellagic acid (4), and

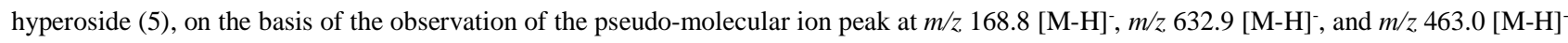
in HPLC/ESI-MS chromatogram, in accordance with the molecular weights of three compounds (gallic acid, coridagin, and hyperoside, Figure 1) occurring in Geranium carolinianum.
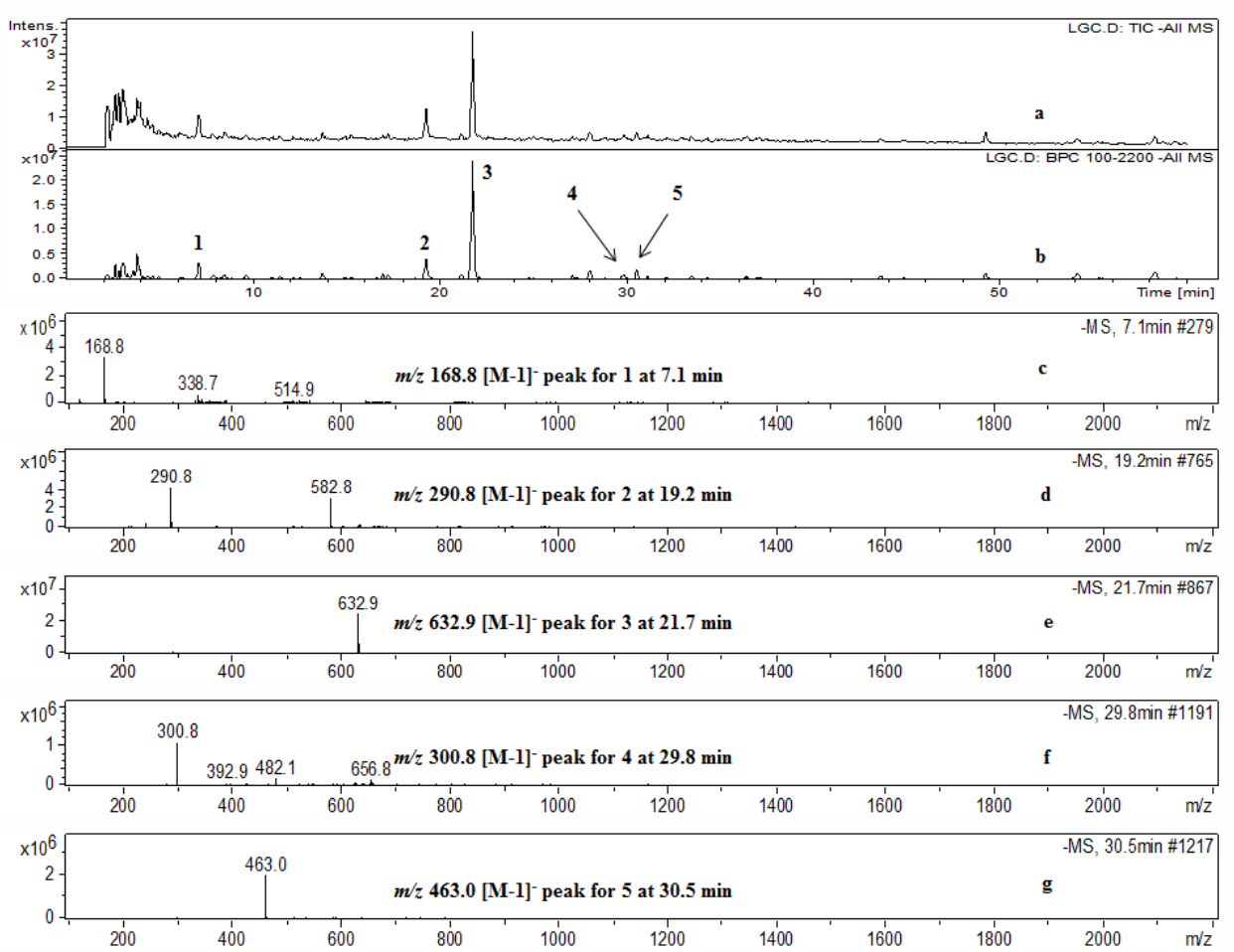

Figure 1: HPLC/ESI-MS chromatogram in negative mode of the extract of Geranium Carolinianum (a: total ion chromatogram b: base peak chromatogram c: ESI-MS spectra of [M-1] $]^{-}$ion of compound 1 (retention time: $7.1 \mathrm{~min}$ ) d: ESI-MS spectra of [M-1] $]^{-}$ion of compound 2

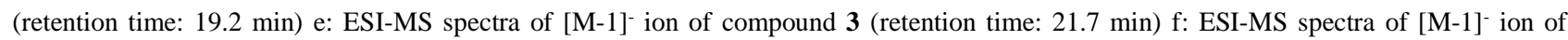
compound 4 (retention time: $29.8 \mathrm{~min}$ ) g: ESI-MS spectra of [M-1]- ion of compound 5 (retention time: $30.5 \mathrm{~min}$ ).

\section{Effect of GCE on the Writhing Reflex of Mice}

As shown in Figure 2, the aqueous extract from Geranium carolinianum (GCE) significantly reduced the number of writhing responses in a dose-dependent manner within 15 min of injection of acetic acid. At the higher dose of GCE, the reduction in writing responses was much more noticeable and was even lower than that of the mice receiving indomethacin, suggesting that GCE has potent analgesic properties. 
Li et al., Afr J Tradit Complement Altern Med. (2016) 13(1):105-113

http://dx.doi.org/10.4314/ajtcam.v13i1.15

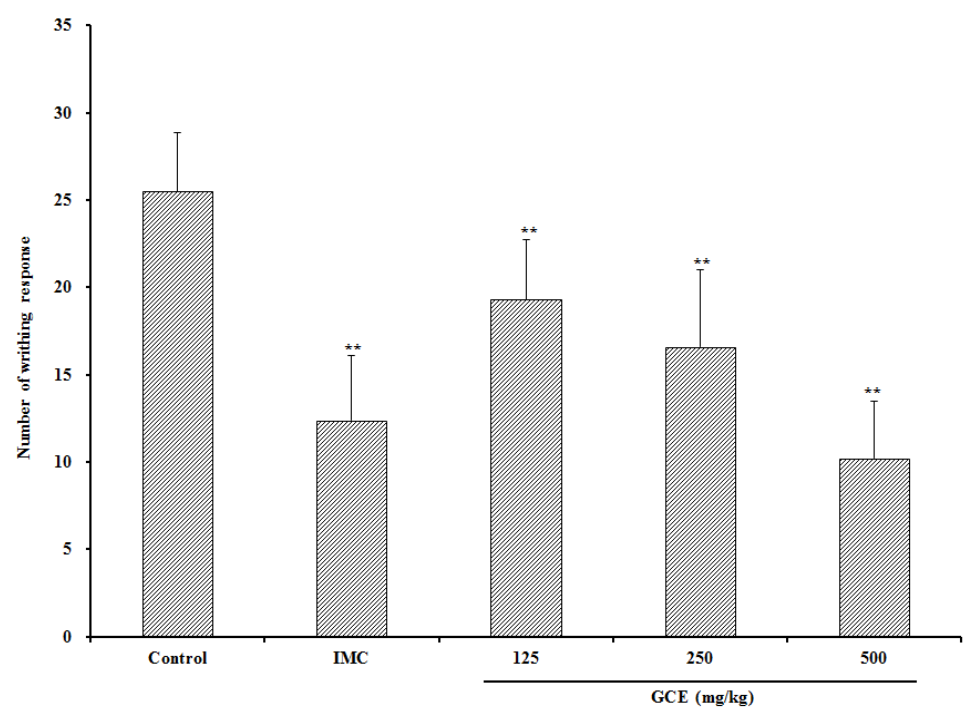

Figure 2: Effects of Geranium carolinianum extract (GCE) on writhing reflex of mice in the writhing test. When mice were given acetic acid $(1 \%, 10 \mathrm{~mL} / \mathrm{kg}$ body weight) intraperitoneally, the writhing number was counted immediately for $15 \mathrm{~min}$. The experiment was repeated twice. $\mathrm{IMC}$ is the abbreviation for indomethacin. Data are presented as mean $\pm \mathrm{SD}, \mathrm{n}=10$. $* * \mathrm{P}<0.01$, significance versus control.

\section{Effect of GCE in Heat-Stimulated Mice}

The analgesic activity of GCE was also markedly observed in the hot-plate test. It was found that GCE at doses of $250 \mathrm{and} 500 \mathrm{mg} / \mathrm{kg}$ body weight prolonged the latency period of mice significantly when compared with the negative group of animals which received distilled water (Figure 3).

\section{Effect of GCE on Fresh Egg White-Induced Paw Edema in Rats}

As shown in Table 1, the sub-plantar injection of $0.1 \mathrm{~mL}$ of fresh egg white noticeably induced paw edema in rats, which had persisted for $6 \mathrm{~h}$. The low dose of GCE ( $125 \mathrm{mg} / \mathrm{kg}$ body weight) evidently decreased the percentage of paw edema only after $2 \mathrm{~h}$ and $3 \mathrm{~h}$ of treatment, and the middle dose $(250 \mathrm{mg} / \mathrm{kg}$ body weight) significantly inhibited paw edema of rats after $1-4 \mathrm{~h}$ of treatment. However, both the high dose of GCE ( $500 \mathrm{mg} / \mathrm{kg}$ body weight) and indomethacin elicited the persistently inhibitory effect on edema formation after $0.5-6 \mathrm{~h}$ of treatment.

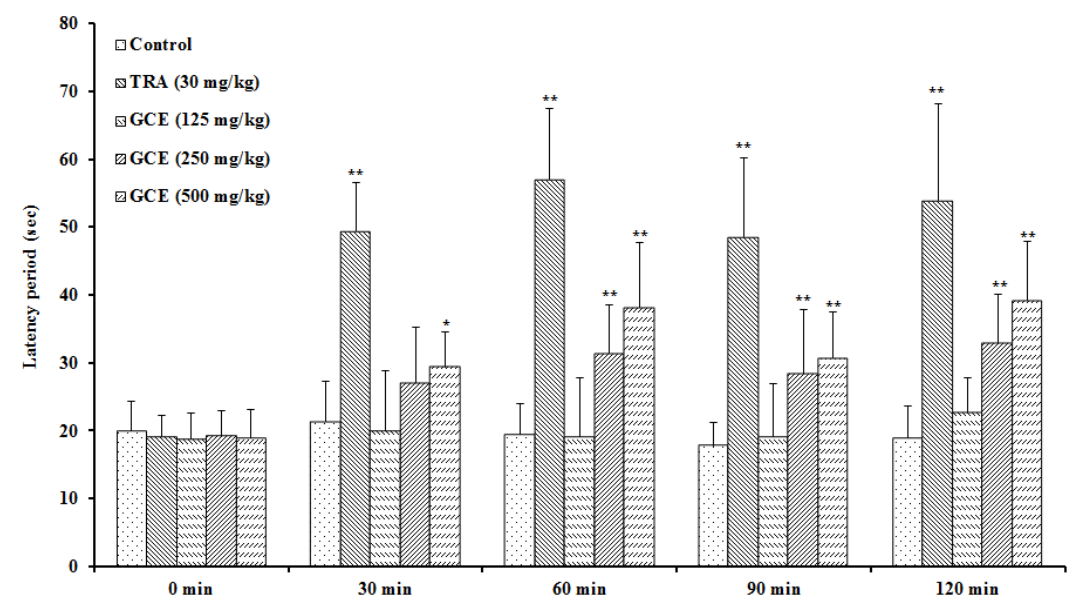

Figure 3: Effects of Geranium carolinianum extract (GCE) on heat-stimulated mice in the hot-plate test. The latency period was recorded when female mice were put on the hot plate maintained at $55 \pm 0.5^{\circ} \mathrm{C}$. TRA is the abbreviation for tramadol. Data are presented as mean $\pm \mathrm{SD}$, 
Li et al., Afr J Tradit Complement Altern Med. (2016) 13(1):105-113

http://dx.doi.org/10.4314/ajtcam.v13i1.15

$n=10 . * P<0.05, * * P<0.01$, significance versus control.

Table 1: Effects of GCE on egg white-induced paw edema in rats

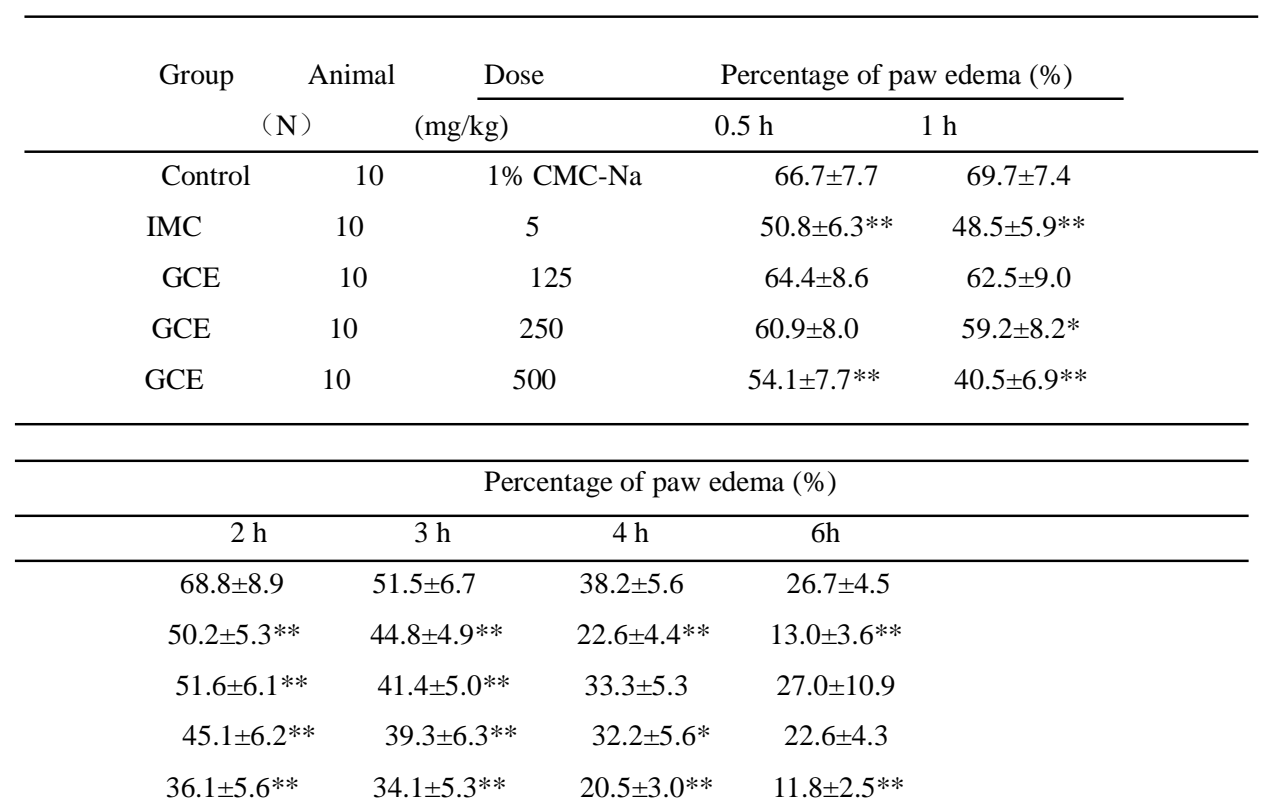

Effects of Geranium carolinianum extract (GCE) on fresh egg white-induced paw edema in rats. When $0.1 \mathrm{ml}$ of freshly prepared $10 \%$ (v/v) egg white solution was injected subplantarly into the right hind paws of male rats, acute inflammation was induced. GCE and indomethacin (IMC) was orally pre-medicated. Data are presented as mean $\pm \mathrm{SD}, \mathrm{n}=10$. $* P<0.05, * * P<0.01$, significance versus control.

\section{Effects of GCE on Dimethylbenzene-Induced Ear Edema in Mice}

Dimethylbenzene evidently increased ear edema in mice; GCE at the doses of 250 and $500 \mathrm{mg} / \mathrm{kg}$ significantly inhibited ear edema compared with the control group. These results reveal that GCE has significant activity against acute inflammation induced by dimethylbenzene (Figure 4).

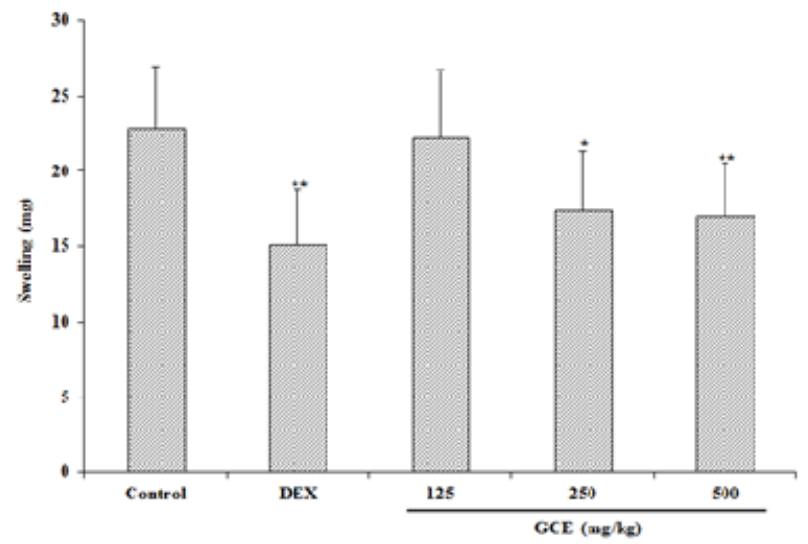

Figure 4: Influence of Geranium carolinianum extract (GCE) on dimethylbenzene-induced ear edema in mice. Mice were given GCE or

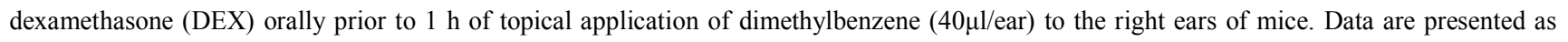
mean $\pm \mathrm{SD}, \mathrm{n}=10 . * \mathrm{P}<0.05, * * \mathrm{P}<0.01$, significance versus control.

\section{Effects of GCE on Fever in Rats}

As shown in Table 2, the temperature in rats was evidently elevated one hour postintraperitoneal injection of LPS and persisted for the following five hours. In contrast to the control group of animals given distilled water, the temperature in the rats receiving GCE significantly 
Li et al., Afr J Tradit Complement Altern Med. (2016) 13(1):105-113

http://dx.doi.org/10.4314/ajtcam.v13i1.15

decreased in a time- and dose-dependent manner. These results indicate that oral administration of GCE inhibits pyrexia induced by LPS.

Table 2: Effects of GCE on temperature in external auditory meatus of rats

\begin{tabular}{|c|c|c|c|c|c|c|c|c|c|c|c|c|c|}
\hline \multirow{2}{*}{\multicolumn{2}{|c|}{$\begin{array}{l}\text { Group } \\
(\mathrm{N})\end{array}$}} & \multirow{2}{*}{$\begin{array}{r}\text { Animal } \\
(\mathrm{mg} / \mathrm{kg})\end{array}$} & \multirow{2}{*}{\multicolumn{2}{|c|}{$\begin{array}{r}\text { Dose } \\
0 \mathrm{~h}\end{array}$}} & \multicolumn{9}{|c|}{ Temperature $\left({ }^{\circ} \mathrm{C}\right)$} \\
\hline & & & & & \multicolumn{2}{|c|}{$0.5 \mathrm{~h}$} & \multicolumn{2}{|l|}{$1 \mathrm{~h}$} & \multicolumn{2}{|c|}{$1.5 \mathrm{~h}$} & \multicolumn{2}{|l|}{$2 \mathrm{~h}$} & \\
\hline \multicolumn{2}{|c|}{ Control } & 10 & \multicolumn{2}{|c|}{$1 \% \mathrm{CMC}-\mathrm{Na}$} & \multicolumn{2}{|c|}{$35.9 \pm 0.3$} & \multicolumn{2}{|c|}{$35.9 \pm 0.4$} & \multicolumn{2}{|c|}{$37.0 \pm 0.4$} & \multicolumn{2}{|c|}{$37.8 \pm 0.4$} & $37.4 \pm 0.2$ \\
\hline \multicolumn{2}{|l|}{$\mathrm{PRC}$} & 10 & \multicolumn{2}{|l|}{100} & \multicolumn{2}{|c|}{$36.0 \pm 0.3$} & \multicolumn{2}{|c|}{$35.4 \pm 0.3 *$} & \multicolumn{2}{|c|}{$35.7 \pm 0.4 * *$} & \multicolumn{2}{|c|}{$35.9 \pm 0.3 * *$} & $35.7 \pm 0.3 * *$ \\
\hline \multicolumn{2}{|l|}{ GCE } & 10 & \multicolumn{2}{|l|}{125} & \multicolumn{2}{|c|}{$35.9 \pm 0.2$} & \multicolumn{2}{|c|}{$35.6 \pm 0.4$} & \multicolumn{2}{|c|}{$36.6 \pm 0.4$} & \multicolumn{2}{|c|}{$37.2 \pm 0.4^{*}$} & $36.8 \pm 0.5^{*}$ \\
\hline \multicolumn{2}{|l|}{ GCE } & 10 & \multicolumn{2}{|l|}{250} & \multicolumn{2}{|c|}{$36.0 \pm 0.3$} & \multicolumn{2}{|c|}{$35.6 \pm 0.3$} & \multicolumn{2}{|c|}{$35.7 \pm 0.3 * *$} & \multicolumn{2}{|c|}{$36.7 \pm 0.4 * *$} & $36.5 \pm 0.5 * *$ \\
\hline \multicolumn{2}{|l|}{ GCE } & 10 & \multicolumn{2}{|l|}{500} & $36.1 \pm$ & $=0.2$ & 35.7 & \pm 0.4 & $36.0 \pm$ & $0.5^{* *}$ & $36.7 \pm$ & $0.4 * *$ & $36.4 \pm 0.4 * *$ \\
\hline Temp & erat & Ire $\left({ }^{\circ} \mathrm{C}\right)$ & & & & & & & & & & & \\
\hline & 31 & & $3.5 \mathrm{~h}$ & $4 \mathrm{~h}$ & & $4.5 \mathrm{~h}$ & & $5 \mathrm{~h}$ & & $5.5 \mathrm{~h}$ & & $6 \mathrm{~h}$ & \\
\hline $3 \pm 0.3$ & 37. & \pm 0.4 & $37.0 \pm 0.4$ & $37.3 \pm$ & & 37.3 & & $37.5 \pm$ & 0.4 & $36.9 \pm$ & 0.3 & $36.8 \pm$ & $=0.3$ \\
\hline $.4 \pm 0.4 * *$ & 35. & $5 \pm 0.3 * *$ & $35.8 \pm 0.4 * *$ & $35.9 \pm$ & $0.4 * *$ & 36.0 & $4 * *$ & $35.5 \pm$ & $0.4 * *$ & $35.9 \pm$ & $0.3 * *$ & $35.9 \pm$ & $=0.4 * *$ \\
\hline $5.7 \pm 0.4 * *$ & & $9 \pm 0.5 * *$ & $36.9 \pm 0.4$ & $37.1 \pm$ & & 36.8 & & $37.2 \pm$ & & 37.0 & \pm 0.5 & $36.4=$ & \pm 0.4 \\
\hline $6.5 \pm 0.5 * *$ & & $6 \pm 0.4^{*}$ & $36.7 \pm 0.3$ & $36.7 \pm$ & $.3 * *$ & 36.2 & $5 * *$ & $36.8 \pm$ & $0.4 * *$ & 36.5 & $\pm 0.4^{*}$ & $36.1=$ & $\pm 0.4 * *$ \\
\hline $36.3 \pm 0.4 * *$ & & $.7 \pm 0.3 *$ & $36.4 \pm 0.5^{*}$ & $36.6 \pm$ & $0.4 * *$ & 36.4 & $.5 * *$ & $37.0 \pm$ & $0.2^{*}$ & 36.6 & \pm 0.3 & 36.1 & $\pm 0.4 * *$ \\
\hline
\end{tabular}

Table 2: Effects of Geranium carolinianum extract (GCE) on temperature in external auditory meatus of rats. The rats were injected with lipopolysaccharides (LPS) after $0.5 \mathrm{~h}$ of the oral administration of GCE or paracetamol (PRC). The temperature was measured every 30 min from 09:00 hrs to 15:00 hrs. Data are presented as mean $\pm \mathrm{SD}, \mathrm{n}=10 . * P<0.05, * * P<0.01$, significance versus control.

\section{Acute Toxicity}

Although the mice were given GCE orally up to $14 \mathrm{~g} / \mathrm{kg}$ body weight which is equivalent to approximately 500 times of clinical dose ( 15 $\mathrm{g} / \mathrm{d}$ herb each adult with $60 \mathrm{~kg}$ body weight), no mortality was observed during the assessment period (7 days). Thus, it can be concluded that oral administration of GCE at this dose is safe.

\section{Discussion}

It is well acknowledged that there is a growing need for safer and more effective drugs to treat pain, inflammation and fever. Due to the inevitable side effects of the drugs currently available, there is a strong interest in medicinal plants with a history of traditional use for the treatment of above diseases. This study was designed to evaluate the analgesic, anti-inflammatory and antipyretic effects of the aqueous extract of Geranium carolinianum (GCE) to give scientific authentication to the traditional claims. In the present study, GCE inhibited the writhing responses in mice in the acetic acid writhing reflex test, increased reaction time in mice in the hot-plate test, and reduced fresh egg white-induced paw edema in rats and dimethylbenzene-induced ear edema in mice. It further attenuated rat pyrexia induced by lipopolysaccharide (LPS), suggesting the favorable analgesic, anti-inflammatory and antipyretic activities of GCE. Additionally, the extract displayed no toxic effects at a dose of $14 \mathrm{~g} / \mathrm{kg}$ body weight, supporting its safety in clinical use. These activities are associated with five main compounds contained in GCE: gallic acid, brevifolin carboxylic acid, corilagin, ellagic acid, and hyperoside (Daud et al., 2006; Gambari et al., 2012; Hsiang et al., 2013; Ku et al., 2014; Trevisan et al., 2014; Zhou et al., 2014).

The acetic acid writhing mice is a classic nonselective analgesic screening model. Acetic acid induces algesia by liberating endogenous substances such as prostaglandinsE $E_{2}$ and many others that stimulate pain nerve endings (Liu et al., 2013). The results show that GCE significantly reduced the number of writhing responses in mice intraperitoneally injected with acetic acid in a dose dependent manner. The analgesic effect of GCE may be due to inhibition of the local level of prostaglandins (Saha et al., 2013).

The hot-plate test method has been applied in analgesic investigations for several decades, which, when compared to the writhing test, can usually distinguish between central and peripheral effects (Srinivasan et al., 2003). The validity of this test has been shown even in the 111 


\section{http://dx.doi.org/10.4314/ajtcam.v13i1.15}

presence of substantial impairment of motor performance (Plummer et al., 1991). In this test, male animals are generally not used because they will lick their scrotums against thermal injury when they touch the heated plate. In this case, a false reaction time of licking the hind paws is often recorded.

Some peripheral analgesic drugs such as aspirin usually have few effects in the hot plated test (Zhu et al., 2011), while some other analgesic drugs such as ibuprofen and tramadol can reduce prostaglandin synthesis via central inhibition of cyclooxygenase, or bind to specific opioid receptors in the central nervous system, exhibiting both peripheral and central analgesic activities (Björkman, 1994). It is clearly demonstrated in our study that GCE at the doses of 250 and $500 \mathrm{mg} / \mathrm{kg}$ body weight significantly prolonged the latency period of mice in the hot plate test, suggesting its centrally analgesic effect.

The rat paw edema induced by fresh egg white is suitable for evaluating anti-inflammatory agents and is used frequently to assess the anti-edematous effect of natural products (Du et al., 2013). It is well known that prostaglandins play an important role in pain progress in chemical nociception models (Santos et al., 1998) and are the target of action of commonly used anti-inflammatory drugs. GCE at the dose of 250 and500 mg/kg body weight markedly reduced egg white-induced paw edema in rats, which lasted for $6 \mathrm{~h}$, indicating that the extract suppresses the release or actions of some of inflammatory mediators, and possibly reduces the release of prostaglandins. The anti-inflammatory activity of the extract was further evidenced by the dimethylbenzene-induced ear edema test, in which GCE at the doses of 250 and $500 \mathrm{mg} / \mathrm{kg}$ body weight also inhibited ear edema of mice markedly. In the process of inflammation, activated neutrophils release mediators such as platelet-activating factor and lysozyme, which can lead to vasodilatation and increase vascular permeability (Saeed et al., 2010).

LPS activates prostaglandin $\mathrm{E}_{2}$ ( $\mathrm{PGE}_{2}$ )-synthesizing enzymes in the lung and liver within minutes of systemic administration followed by $\mathrm{PGE}_{2}$ which originates peripherally and is delivered to the brain by albumin or by locally influenced nerve fibers such as hepatic vagal fibers. Hepatic fibers contain PG receptors of the EP3 type causing pyrexia (Dogan et al., 2004). In our study, LPS-induced fever was employed to investigate the antipyretic activity of GCE and the results presented in Table 2 indicate that GCE possesses significant antipyretic action.

In addition, the acute toxicity study revealed that GCE did not cause any toxic effects as judged by the lack of fatalities in mice at a dose of $14 \mathrm{~g} / \mathrm{kg}$ body weight (approximately 553 times of clinical dose), thus displaying good safety.

In conclusion, our study demonstrates that GCE exerts favorable analgesic, anti-inflammatory, and antipyretic activities possibly by inhibition of the central synthesis of prostaglandins, which are involved in five identified compounds contained in this extract. This validates the claim by traditional medicine practitioners that GCE can be used to treat rheumatic arthralgia and febrile diseases. However, detailed studies are needed to elucidate the mechanisms of action responsible for the analgesic, anti-inflammatory, and antipyretic activities exhibited by the aqueous extract of Geranium carolinianum.

Conflict of Interest Statement: The authors report no conflict of interest.

Acknowledgment: This work was supported by the National Natural Science Foundation of China (No. 81173462) and the funds from the Shanghai Municipal Science and Technology Commission (15401971800 and 15401902700), Shanghai Municipal Health and Family Planning Commission (ZY3-JSFC-2-2010, 20134090 and ZYXK2012010) and Pudong New Area Health and Family Planning Commission

(PWZz2013-02 and PWRd2013-03).

\section{References}

1. Björkman, R. (1994). Central antinociceptive effects of non-steroidal anti-inflammatory drugs and paracetamol. Experimental studies in the rat. Acta. Anaesth. Scand. 103:1-44.

2. Daud, A., Habib, N., Riera, A.S. (2006). Anti-inflammatory, anti-nociceptive and antipyretic effects of extracts of Phrygilanthus acutifolius flowers. J Ethnopharmacol. 108:198-203.

3. Dogan, M.D., Patel, S., Rudaya, A.Y., Steiner, A.A., Székely, M., Romanovsky, A.A. (2004). Lipopolysaccharide fever is initiated via a capsaicin-sensitive mechanism independent of the subtype-1 vanilloid receptor. Brit. J. Pharmacol. 143:1023-1032.

4. Du, Q.H., Peng, C., Zhang, H. (2013). Polydatin: A review of pharmacology and pharmacokinetics. Pharm. Biol. 51:1347-1354.

5. Gambari, R., Borgatti, M., Lampronti, I., Fabbri, E., Brognara, E., Bianchi, N., Piccagli, L., Yuen, M.C.W., Kan, C.W., Hau, D.K.P. (2012). Corilagin is a potent inhibitor of NF-kappaB activity and downregulates TNF-alpha induced expression of IL-8 gene in cystic fibrosis IB3-1 cells. Int. 


\section{http://dx.doi.org/10.4314/ajtcam.v13i1.15}

\section{Li et al., Afr J Tradit Complement Altern Med. (2016) 13(1):105-113}

Immunopharmacol. 13:308-315.

6. Garcia, M., Fernandez, M., Alvarez, A., Saenz, M. (2004). Antinociceptive and anti-inflammatory effect of the aqueous extract from leaves of Pimenta racemosa Var. Ozua (Mirtaceae). J. Ethnopharmacol. . 91:69-73.

7. Han, G.X., Wan, L.X., Zhang, W.D., Liu, W.Y., H.S., C. (2001). The research survey of Geranium carolinianum L. J. Pharm. Pract. 19:31-31.

8. He, W.T., Jin, Z.X., Wang, B.Q. (2011). Research progress of Geranii Herba. J. Aerospace. 22:1200-1202.

9. Hsiang, C.Y., Hseu, Y.C., Chang, Y.C., Kumar, K.S., Ho, T.Y., Yang, H.L. (2013). Toona sinensis and its major bioactive compound gallic acid inhibit LPS-induced inflammation in nuclear factor- $\kappa \mathrm{B}$ transgenic mice as evaluated by in vivo bioluminescence imaging. Food. Chem. 136:426-434.

10. Ku, S.K., Kwak, S., Kwon, O.J., Bae, J.S. (2014). Hyperoside Inhibits High-Glucose-Induced Vascular Inflammation In Vitro and In Vivo. Inflammation. 37:1389-1400.

11. Lei, Z.Y., Liu, D.L., Hu, Y.Q., Cui, L.G. (2002). Advance in study on chemical constituent and pharmacologic effects of Geranium carolinianum L. J. Chin. Med. Mater. 25:759-761.

12. Li, J., Huang, H., Zhou, W., Feng, M., Zhou, P. (2008). Anti-hepatitis B virus activities of Geranium carolinianum L. extracts and identification of the active components. Biol. Pharm. Bull. 31:743-747.

13. Li, Y., Xu, H.J., Yang, Y.A., Zhang, X.Q., Li, X.Z., Wang, Y., Song, W. A New Geranium carolinianum L. Extract. Chinese Patent ZL 200810122739.4, 30 December 2009.

14. Liu, K.Y., Hu, S., Chan, B.C., Wat, E.C., Lau, C., Hon, K.L., Fung, K.P., Leung, P.C., Hui, P.C., Lam, C.W. (2013). Anti-inflammatory and anti-allergic activities of Pentaherb formula, Moutan Cortex (Danpi) and gallic acid. Molecules. 18:2483-2500.

15. Ma, K.J., Zhu, Z.Z., Yu, C.H., Zhang, H., Liu, J., Qin, L.P. (2011). Analgesic, anti-inflammatory, and antipyretic activities of the ethanol extract from Desmodium caudatum. Pharm. Biol. 49:403-407.

16. Plummer, J.L., Cmielewski, P.L., Gourlay, G.K., Owen, H., Cousins, M.J. (1991). Assessment of antinociceptive drug effects in the presence of impaired motor performance. J. Pharmacol. Meth. . 26:79-87.

17. Saeed, M.K., Deng, Y., Dai, R., Li, W., Yu, Y., Iqbal, Z. (2010). Appraisal of antinociceptive and anti-inflammatory potential of extract and fractions from the leaves of Torreya grandis Fort Ex. Lindl. J. Ethnopharmacol. . 127:414-418.

18. Saha, S., Hossain, F., Anisuzzman, M., Islam, M.K. (2013). Pharmacological evaluation of Musa seminifera Lour. fruit. Journal of integrative medicine. 11:253-261.

19. Santos, A., Vedana, E., De Freitas, G. (1998). Antinociceptive effect of meloxicam, in neurogenic and inflammatory nociceptive models in mice. Inflamm. Res. 47:302-307.

20. Srinivasan, K., Muruganandan, S., Lal, J., Chandra, S., Tandan, S., Raviprakash, V., Kumar, D. (2003). Antinociceptive and antipyretic activities of Pongamia pinnata leaves. Phytother. Res. 17:259-264.

21. Trevisan, G., Rossato, M.F., Tonello, R., Hoffmeister, C., Klafke, J.Z., Rosa, F., Pinheiro, K.V., Pinheiro, F.V., Boligon, A.A., Athayde, M.L. (2014). Gallic acid functions as a TRPA1 antagonist with relevant antinociceptive and antiedematogenic effects in mice. Naunyn. Schmiedebergs. Arch. Pharmacol. 387:679-689.

22. Wang, Y.L., Lu, M.M. (1995). Experimental study on inhibitory effect of Chinese herbs on herpes simplex virus. J. Tradi .Chin. Ophthalmo. 5:78-82.

23. Wu, Q.Y., Zhou, Y., Jin, X., Guan, Y., Xu, M., Liu, L.F. (2011). Chromatographic fingerprint and the simultaneous determination of five bioactive components of Geranium carolinianum L. water extract by high performance liquid chromatography. Int. J. Mol. Sci. 12:8740-8749.

24. Wu, Y.T., Jin, Z.X. (2008). The research progrosss of tannins and its and pharmacological activities from Geranium carolinianum L. Heilongjiang. Med. 21:67-68.

25. Xu, S.Y., Bian, R.L.,Chen, X. (2002) Experimental Methodology of Pharmacology (third version). Peoples' Medical Publishing House, Beijing, $886-887$.

26. Zheng, C.J., Tang, W.Z., Huang, B.K., Han, T., Zhang, Q.Y., Zhang, H., Qin, L.P. (2009). Bioactivity-guided fractionation for analgesic properties and constituents of Vitex negundo L. seeds. Phytomedicine. 16:560-567.

27. Zhou, E., Fu, Y., Wei, Z., Yang, Z. (2014). Inhibition of allergic airway inflammation through the blockage of NF- $\mathrm{kB}$ activation by ellagic acid in an ovalbumin-induced mouse asthma model. Food. Funct. . 5:2106-2112.

28. Zhu, Z.Z., Ma, K.J., Ran, X., Zhang, H., Zheng, C.J., Han, T., Zhang, Q.Y., Qin, L.P. (2011). Analgesic, anti-inflammatory and antipyretic activities of the petroleum ether fraction from the ethanol extract of Desmodium podocarpum. J. Ethnopharmacol. 133:1126-1131. 